\title{
The Outcomes of Selective Nerve Root Block for Disc Induced Lumbar Radiculopathy
}

\author{
Arun-Kumar K, MS Orth, Jayaprasad S, MS Orth, Senthil K, MS Orth, Lohith H, D Orth, \\ Jayaprakash KV, MS Orth \\ Department of Orthopaedics, Melmaruvathur Adhiparasakthi Institute of Medical Sciences and Research, \\ Melmaruvathur, India
}

\author{
(c) (1) \\ Date of submission: July 2015 \\ Date of acceptance: October 2015
}

\begin{abstract}
Introduction : Use of Selective Nerve Root Block (SNRB) in lumbar region to relieve radicular pain along the course of a particular nerve is being practiced in the recent past. We observed and tabulated therapeutic outcomes of this procedure in management of radiculopathy induced by a prolapsed disc affecting a particular lumbar nerve root.
\end{abstract}

Methods : 40 patients with various grades of disc prolapse affecting a particular lumbar nerve root presenting with chronic radicular pain were identified irrespective of age and sex. All were injected with a combination of $40 \mathrm{mg}$ of Methylprednisolone based suspension with local anaesthetic over the affected nerve root and results were analyzed.

Results : Those graded mild had 4.3 months relief and those graded moderate had 2.5 months relief. Those with severe disc prolapse had no relief except for the immediate postprocedural relief. Only $20 \%$ patients had relief up to 6 months.

Conclusion : Effect of SNRB is typically short acting in majority of patients and recurrence is expected. It creates a window period with reduced pain but of varied intervals depending on the pathology. It did not alter the prognosis in those with severe disease where surgery is well indicated.

Level of Evidence - Level 4

Key Words:

Selective Nerve Root Block, Disc prolapse, Radicular Pain, Lumbar Radiculopathy

\section{INTRODUCTION}

Lumbar radiculopathy can be defined as pain from lower back radiating until the leg or further beyond along the course of a particular lumbar nerve. Selective Nerve Root Block (SNRB) is practiced as a part of the management of radicular pain due to a particular affected nerve root in both cervical and lumbar regions ${ }^{1-3}$. Although its specificity as a diagnostic tool is said to be low, Therapeutic efficacy needs to be debated ${ }^{4,5}$. It is used invariably for those with or without significant surgical spinal lesions ${ }^{6}$. Mechanical lesions include various stages of disc prolapse, ligamentum flavum hypertrophy, facet hypertrophy and degenerative osteophytes causing foraminal stenosis, all leading to nerve root irritation ${ }^{7}$. Inflammatory response to exposed nucleus pulposus is also said to contribute to the nerve root pain ${ }^{7}$. The principle behind this technique is to reduce inflammation of the nerve root by injecting a steroid and thus reducing the intensity of pain. But the actual pathology causing the nerve root irritation remains and hence recurrence is expected. Our aim is to study the prognosis after single dose of SNRB over affected lumbar nerve roots and find out whether a window period of reduced pain be achieved before proceeding to next line of management.

\section{MATERIALS AND METHODS}

Selection criteria of our patients were irrespective of age and sex. Those patients with complaints of lumbar radiculopathy for more than 3 months demonstrating a positive unilateral Straight Leg Raising test (SLRT) within 30-60 degrees were selected. MRI was done in all patients as a standard protocol to look for mechanical lesions. Only those patients with intervertebral disc lesions affecting a particular lumbar nerve root were selected for the study. Those with more of back pain component than radiating pain were excluded. Those with bilateral symptoms, multiple nerve root involvement and neurological weakness were excluded. We used the MSU Classification for herniated lumbar discs on MRI to grade our patients (Table I) ${ }^{8}$.

Corresponding Author: Arun Kumar K, 98, Bharathisalai, Nolambur Phase 2, Mogappair West Garden, Mogappair, Chennai, Tamil Nadu, 600037, India

Email: dr.arunkumar.orth@gmail.com 
Our study group consisted of 40 patients, 9 male and 31 female. Age of our patients was between $23-61$ years with mean age being 42.6 years. 23 patients had right sided radiculopathy and 17 patients had left sided radiculopathy. All patients were given the Roland Morris Disability questionnaire (RMDQ) for back pain and their score was recorded before the procedure ${ }^{9}$. Numeric rating scale (NRS) for pain was used to grade pre procedure pain on doing SLR ${ }^{10}$. Radiological lesion in 15 patients was type $1 \mathrm{~B}$ prolapse (Fig 1a) and in 18 patients was either $2 \mathrm{~B}$ or $2 \mathrm{AB}$ prolapse (Fig 1b). The remaining 7 patients had a $3 \mathrm{~B}$ or $3 \mathrm{AB}$ prolapse (Fig 1c) where surgery is very well indicated but were not willing to proceed with immediate surgery. Our sample did not contain patients of all 10 types described in the classification. For discussion purpose we describe those with type $1 \mathrm{~B}$ prolapse as mild, those with $2 \mathrm{~B}$ or $2 \mathrm{AB}$ prolapse as moderate and those with $3 \mathrm{~B}$ or $3 \mathrm{AB}$ prolapse as severe (Fig 1). Procedure took not more than 15 minutes.

All selected patients had previously undergone a course of conservative management with rest and physiotherapy which did not relieve their symptoms. 32 patients had L4-L5 disc prolapse which usually affects the L5 nerve root that traverses at that level and exits below the L5 pedicle. 8 patients had L5-S1 disc prolapse that usually affects the S1 nerve root that exits in the first dorsal sacral foramina. Our sample did not have patients with pathology at any other level except for L4-L5 and L5-S1 and hence our target nerve roots were L5 and S1. None of our patients had a L4-L5 far lateral disc prolapse affecting the L4 root and none had a L5$\mathrm{S} 1$ far lateral disc prolapse affecting the L5 root.

Our procedure to target L5 and S1 roots differs. It is always done under C-Arm guidance but the position of $\mathrm{C}$-arm and direction of exposure varies (Fig 2). Patient is made to lie down prone and their lumbosacral spine region is prepared and draped. C-Arm is positioned for an antero-posterior (AP) view of the lumbosacral junction (Fig 2a). Targeting the affected L5 nerve root requires identification of L5 pedicle on that side in an AP C-Arm image. The L5 nerve usually exits below and close to the L5 pedicle. Adequate local anaesthetic was infiltrated under the skin $3-4 \mathrm{cms}$ lateral to the inferior border of L5 pedicle where we usually enter. An 18 gauge spinal needle was introduced and directed to a point few millimeters below and lateral to the L5 pedicle where the nerve is usually found. If bony resistance is felt then the needle is walked over the bone to reach the desired point. Targeting S1 nerve root requires the C-Arm to be tilted perpendicular to the sacrum so that there is a clear view of the first dorsal sacral foramina (Fig 2b). Here the needle is directed into the first dorsal foramina where S1 exits.

Patient is cautioned about the paresthesia which will be felt along the course of their radicular pain when the needle touches the nerve and due to this reason we were very cautious not to handle the needle vigorously. This is to prevent injury to the nerve caused by the needle. A lateral view was taken occasionally to confirm position of the needle in circumstances when there was difficulty in eliciting paresthesia (Fig 2c). Once paresthesia is elicited, needle is slightly withdrawn and $0.5 \mathrm{ml}$ of Iohexol (an iodine based radiopaque dye) is injected to confirm the position of needle ${ }^{11}$. Various patterns of contrast material distribution around the nerve were seen as shown in literature (Fig 3) ${ }^{10}$. Then a combination of $40 \mathrm{mg}$ of Methyl prednisolone based suspension with local anaesthetic was injected over the affected nerve root. Post procedure parasthesia due to local anaesthetic effect is expected.

Numeric rating of pain using NRS on doing SLRT was used to analyze immediate effect of this procedure. Most of the patients were discharged on the day of procedure and were asked to be in rest for the first 2 days. They were asked to review after 2 days if symptoms remain unchanged or after a week if improvement is felt. Patients were given the Roland Morris Disability questionnaire for back pain and their score was recorded every week in the first month after procedure and every month thereafter. Those with unchanged symptoms and recurrence went for a subsequent decompression surgery and remaining patients were warned about recurrence of symptoms.

\section{RESULTS}

Mean numeric rating of pain using NRS before the procedure on doing straight leg raising on the affected side was 8. Mean pre procedural Roland Morris Disability questionnaire score was 23. 32 patients $(80 \%)$ had L4 L5 intervertebral disc prolapse in whom L5 nerve root was targeted. 8 patients (20\%) had L5 S1 disc prolapse in whom S1 nerve was targeted. Mean numeric rating of pain using NRS immediately after the procedure on doing straight leg raising on the affected side was reduced to 4 which is due to the local anaesthetic effect. NRS assessment on doing SLR was done on 2 nd day after the procedure for 7 patients who returned with similar pain. It was found to be the same as pre procedural status or one point less. They were given reassurance and were asked to wait until one week is complete for RMDQ score. All patients were reviewed after one week and were given the Roland Morris Disability questionnaire for back pain and their score was noted. Mean overall RMDQ score at 1 week was 10.35 which denote improvement. Those with full recurrence in subsequent follow ups having RMDQ scores more than 20 were excluded from our sample to proceed to next line of management which is not discussed in this article.

Even though overall RMDQ score denotes improvement by 1 week, 7 patients had RMDQ Score of 20 or more. These patients were the ones considered severe in whom surgery was indicated but were not willing to proceed with immediate surgery. All these patients had full recurrence 
Table I: Grading of herniated discs based on MRI

\begin{tabular}{|lll|}
\hline No. Of Patients & Grade & $\begin{array}{c}\text { Table I - Grading } \\
\text { Type Of Prolapse Based On Msu Classification }\end{array}$ \\
\hline 15 & Mild & Type 1b Prolapse \\
18 & Moderate & Type 2b/2ab Prolapse \\
7 & Severe & Type 3b/3ab Prolapse \\
\hline
\end{tabular}

Table II: Change in RMDQ score with follow up

\begin{tabular}{|lccc|}
\hline & \multicolumn{2}{c|}{ Table II - Analysis } & Mean RMDQ Score \\
\hline Follow Up & No Of Patients With Relief & Percentage & 8.1 \\
3 Weeks & 33 & 82.5 & 6.2 \\
1 Month & 33 & 82.5 & 7.9 \\
2 Months & 29 & 72.5 & 6.8 \\
3 Months & 19 & 47.5 & 9 \\
4 Months & 13 & 32.5 & 8.4 \\
5 Months & 8 & 20 & 11.8 \\
6 Months & 8 & 20 & 15 \\
\hline
\end{tabular}

Table III: Outcome grading based on duration of pain relief

\begin{tabular}{|ll|}
\hline & Table III - Results Based On Pathology \\
\hline Grade & Mean Duration Of Relief \\
Mild & 4.3 Months \\
Moderate & 2.5 Months \\
Severe & Only Immediate Post Procedural Relief \\
\hline
\end{tabular}

after 1st week with RMDQ score of 22 or more. They were explained about their poor outcome and all of them opted for a surgical decompression. On excluding those 7 patients with recurrence our sample reduced to 33 patients $(82.5 \%)$ with a mean RMDQ score of 8.1 by 2 weeks and 6.2 by 3 weeks. Review at one month had 4 patients with RMDQ scores more than 20. Hence they were excluded for further management reducing our sample size to 29 patients (72.5\%). The mean RMDQ score of the reduced sample was 7.8 by 1 month.

Next follow up was by 2 months which had 10 patients with RMDQ scores more than 20. They were excluded and our group reduced to 19 patients $(47.5 \%)$ with mean RMDQ score of 6.8. Six patients had recurrence at 3 months reducing our group to $13(32.5 \%)$. Mean RMDQ score of the remaining 13 was 9 . By 4 months, 5 more patients had RMDQ score more than 20. Hence our group reduced to 8 patients $(20 \%)$ with mean 4 month RMDQ score of 8.4 . These 8 patients were seen at 5 months with mean RMDQ Score of 11.8 and at 6 months with mean RMDQ score of 15 . Patients with non-surgical radiological lesions who had symptoms after 6 months were given choice of a 2nd dose SNRB and all of them opted. They were explained about our results and prognosis.

Analyzing results showed that $82.5 \%$ patients had improvement by 2 weeks which reduced to $72.5 \%$ by 1 month (Table II). Sequential follow up revealed constant decrease in the percentage of patients with relief. Only $47.5 \%$ of patients had relief by 2 months which reduced to $32.5 \%$ by 3 months and to $20 \%$ by 4 months. Finally only 20 percent patients remained at 6 months progressing slowly back to pre-procedural status. The last $20 \%$ patients were those with mild protruding disc towards one side. According to our description based on MSU Classification, those graded mild had 4.3 months relief and those graded moderate had 2.5 months relief. Those with severe disc prolapse in whom surgery is indicated had no relief except for the immediate post-procedural relief (Table III).

\section{DISCUSSION}

Lumbar radiculopathy is a very common condition seen in our orthopaedic clinic. We see an increased incidence in patients presenting with this condition. Conservative management in these patients is highly unpredictable. Most patients do not accept surgery in first place and there are circumstances where we feel surgery is not yet indicated. Such patients require something that will relieve their pain at least for a short duration. SNRB plays an important therapeutic role in these patients. As the actual pathology causing the nerve root irritation remains, prognosis in these patients varies.

Many authors have used methyl prednisolone based preparations for this purpose ${ }^{12}$. Triamcinolone and 


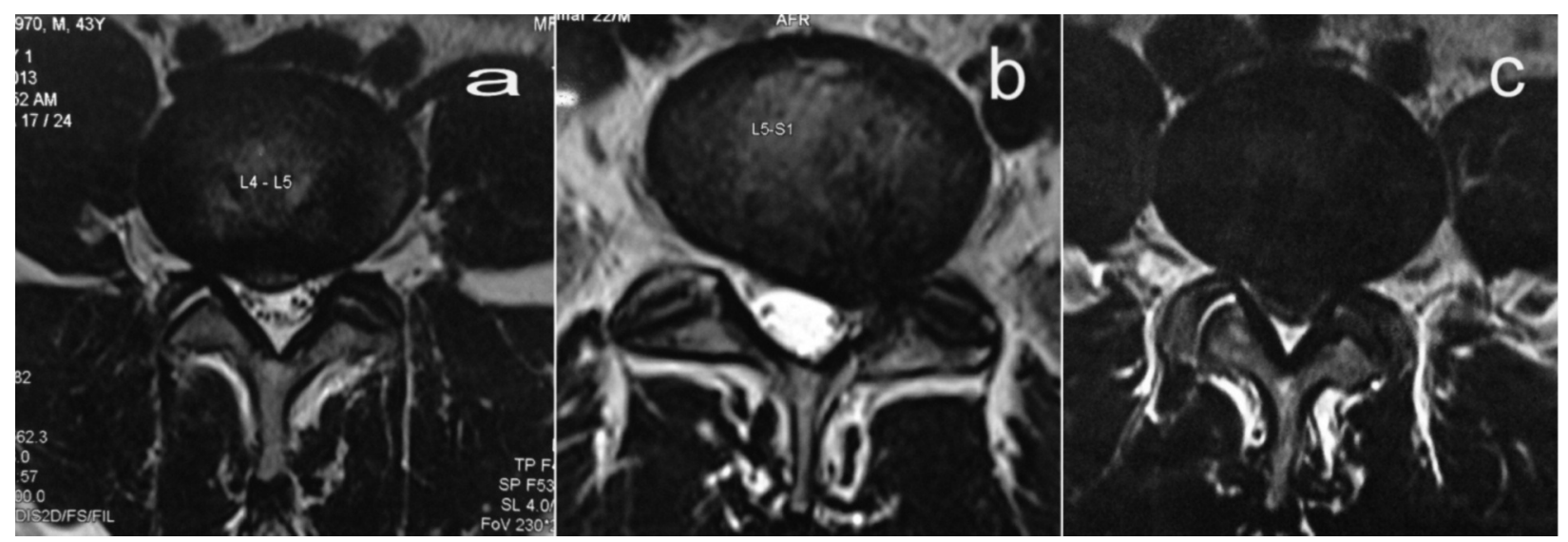

Fig. 1: Figure 1a : Mild disc prolapse.

Figure 1b: Moderate disc prolapse.

Figure 1c: Severe disc prolapse.

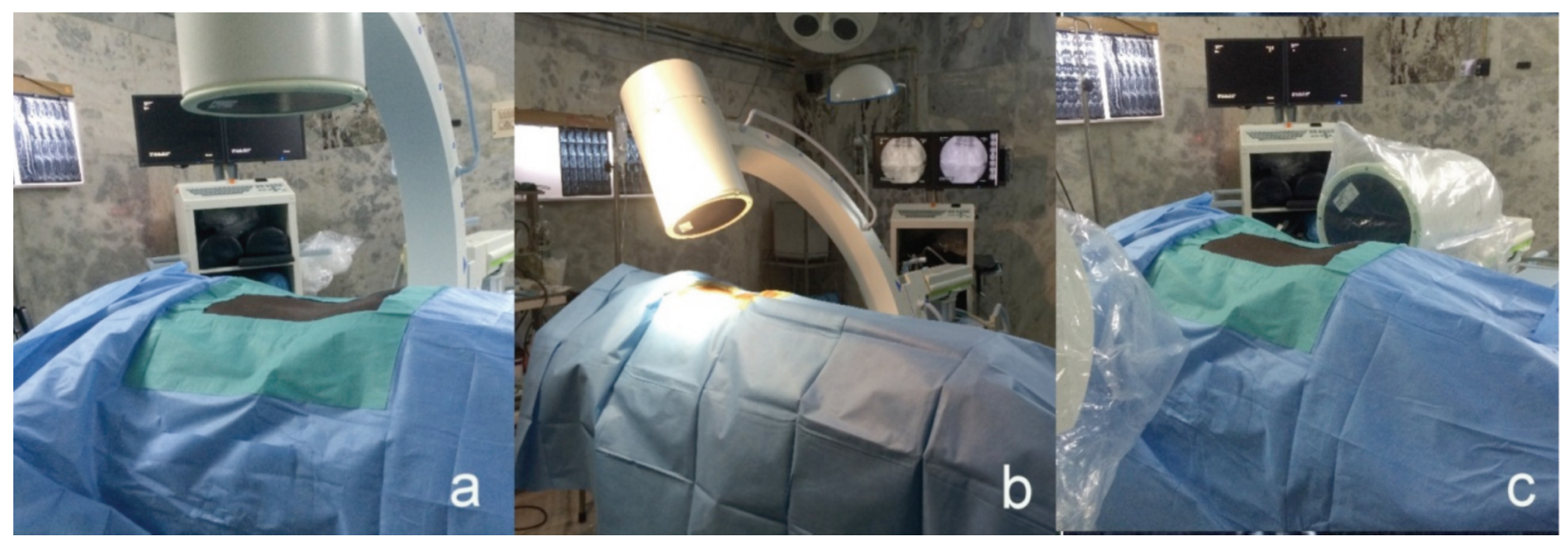

Fig. 2: Figure 2a : C-Arm positioned for an anteroposterior (AP) view to target $L 5$.

Figure $2 \mathrm{~b}: \mathrm{C}$ - Arm in 30 degree caudal tilt for obtaining true AP view of sacrum to target $\mathrm{S} 1$.

Figure 2c: C-Arm positioned for lateral view.

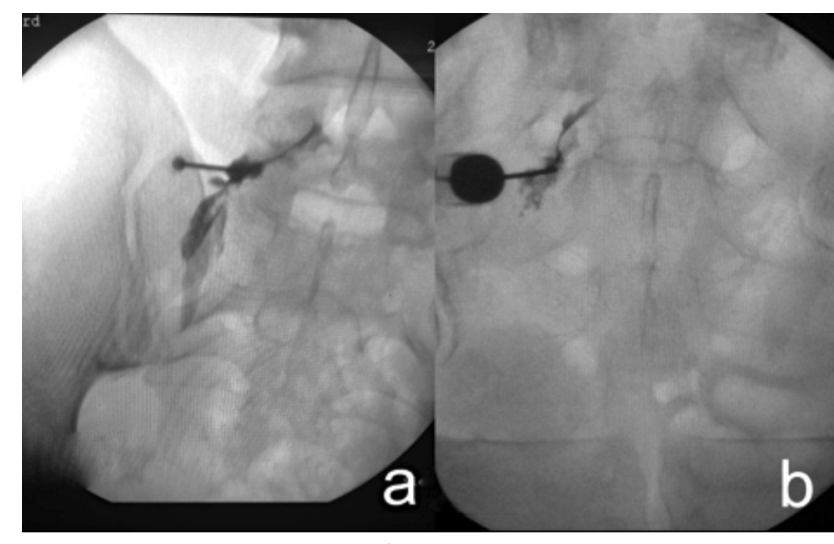

Fig. 3: Figure 3a - Spread of dye along L5 root Figure $3 \mathrm{~b}-$ Spread of dye along $\mathrm{S} 1$ root

betamethasone based preparations are also in use ${ }^{13}$. Easy availability in our institute made us to choose a methyl prednisolone based aqueous suspension for this purpose. For obtaining therapeutic effect, we used $40 \mathrm{mg}$ of steroid for one SNRB. To be more precise, we always looked for paresthesia when the needle touches the nerve root and then withdrew the needle slightly before injecting the dye. Care is taken not to handle the needle vigorously when around the nerve root as we expect a mere touch with the root. Most authors say that this should not be done to prevent needle induced complications but we did not have any such complications ${ }^{11,14}$.

We used the numeric pain rating scale for pre procedural and post procedural assessment of pain ${ }^{10}$. The pain rating can be obtained by asking the patient to choose a number between 0 to 10 with 0 being no pain and 10 being severe pain. But our main aim was to concentrate on the functional outcome and hence we used the Roland Morris Disability Questionnaire ${ }^{15}$. This method is useful in circumstances when the patient is not able to come for follow up. It has a set of 24 questions that is asked to the patient mainly on functional aspects. Patients just need to reply yes or no for this questions hence a telephonic conversation with the patients is enough to collect data. The higher the number of Yes, the severe is the problem. Clinical improvement over time can be graded based on the analysis of serial questionnaire score ${ }^{15}$. 
As noted by few other authors, early response did not predict the effect after 2 weeks ${ }^{11}$. There were patients with severe pain during first follow up who gradually improved and there were also patients with good relief gradually worsen. Those with severe disc prolapse who were not willing for surgery neither responded nor gained any interval period with reduced pain except for the immediate post procedural relief. This immediate relief can be considered as a diagnostic tool to confirm that the blocked root is the affected one that needs to be decompressed. It correlates with the amount of relief the patient will have if that particular nerve root is decompressed surgically. Those with mild and moderate prolapse showed similar results gaining them an interval period with reduced pain which allowed most of our patients to think about next line of management if their pain comes back.

\section{CONCLUSION}

The effect is typically short acting in majority of patients yet it gains a valuable interval period of reduced pain in those patients with mild and moderate pathology. This procedure can be effectively used as an intermediate procedure before going for surgery in those patients with inconclusive radiological indication for surgery. It does not alter the prognosis in those with severe disease where surgery is well indicated.

\section{ACKNOWLEDGEMENTS}

We sincerely thank our Professor Dr. C.S. Krishnamurthy for his motivation and guidance. We are thankful to Dr. Venkatesh, Dr. A. Sivakumar and Dr. Muthu for their assistance in all our cases.

\section{REFERENCES}

1. Chung JY, Yim JH, Seo HY, Kim SK, Cho KJ. The Efficacy and Persistence of Selective Nerve Root Block under Fluoroscopic Guidance for Cervical Radiculopathy. Asian Spine J. 2012; 6: 227-32.

2. L Anderberg, M Annertz, L Persson, L Brandt, H Saveland. Transforaminal steroid injections for the treatment of cervical radiculopathy: a prospective and randomised study. Eur Spine J. 2007; 16: 321-8.

3. Narozny M, Zanetti M, Boos N. Therapeutic efficacy of selective nerveroot blocks in the treatment of lumbar radicular leg pain. Swiss Med Weekly 2001; 131: 75-80.

4. Beynon R, Hawkins J, Laing R, Higgins N, Whiting P, Jameson C, et al. The diagnostic utility andcost-effectiveness of selective nerve root blocks in patients considered for lumbar decompression surgery: a systematic review and economic model. Health Technol Assess 2013; 17(19).

5. Datta S, Manchikanti L, Falco FJ, Calodney AK, Atluri S, Benyamin RM, et al. Diagnostic Utility of Selective Nerve Root Blocks in the Diagnosis of Lumbosacral Radicular Pain: Systematic Review and Update of Current Evidence. Pain Physician 2013; 16 (2 Suppl): SE97-124.

6. Epstein NE. The risks of epidural and transforaminal steroid injections in the Spine: Commentary and a comprehensive review of the literature. Surg Neurol Int 2013; 4: 74-93.

7. Stafford MA, Peng P, Hill DA. Sciatica: a review of history, epidemiology, pathogenesis, and the role of epidural steroid injection in management. Br J Anaesth. 2007; 99: 461-73.

8. Mysliwiec LW, Cholewicki J, Winkelpleck MD, Eis GP. MSU classification for herniated lumbar discs on MRI: Toward developing objective criteria for surgical selection. Eur Spine J 2010;19: 1087-1093.

9. Roland M, Morris R. A study of the natural history of back pain. Part I: development of a reliable and sensitive measure of disability in low-back pain. Spine 1983; 8: 141-4.

10. Hawker GA, Mian S, Kendzerska T, French M. Measures of adult pain: Visual Analog Scale for Pain (VAS Pain), Numeric Rating Scale for Pain (NRS Pain), McGill Pain Questionnaire (MPQ), Short-Form McGill Pain Questionnaire (SF-MPQ), Chronic Pain Grade Scale (CPGS), Short Form-36 Bodily Pain Scale (SF-36 BPS), and Measure of Intermittent and Constant Osteoarthritis Pain (ICOAP). Arthritis Care Res. 2011; 63: 240-252.

11. Pfirrmann CW, Oberholzer PA, Zanetti M, Boos N, Trudell DJ, Resnick D, et al. Selective nerve root blocks for the treatment of sciatica: evaluation of injection site and effectiveness--a study with patients and cadavers. Radiology. 2001 Dec; 221(3): 704-11. 
12. Mobaleghi J, Allahdini F, Nasseri K, Ahsan B, Shami S, Faizi M, et al. Comparing the effects of epidural methylprednisolone acetate injected in patients with pain due to lumbar spinal stenosis or herniated disks: a prospective study. Int J Gen Med. 2011; 4: 875-8. doi: 10.2147/IJGM.S25929. Epub 2011 Dec 20.

13. Blankenbaker DG, De Smet AA, Stanczak JD, Fine JP. Fine. Lumbar Radiculopathy: Treatment with Selective Lumbar Nerve Blocks- Comparison of Effectiveness of Triamcinolone and Betamethasone Injectable Suspensions. Radiology 2005; 237: 73841.

14. Slipman CW, Issac Z.. The Role of Diagnostic Selective Nerve Root Blocks in the Management of Spinal Pain. Pain Physician 2001; 4: 214-26.

15. M Roland, J Fairbank. The Roland Morris Disability Questioinaire and the Oswestry Disability Questionaire. Spine 2000; 25: 3115-24. 